\title{
Functional foods: Latin American perspectives
}

\author{
Franco M. Lajolo* \\ Departamento de Alimentos e Nutrição Experimental, Faculdade de Ciências Farmacêuticas, \\ Universidade de São Paulo, Av. Prof. Lineu Prestes 580, Bl. 14, 05508-900 São Paulo, Brazil
}

\begin{abstract}
The perspectives of Latin America as a potential producer and consumer of functional foods will depend largely on the level of information and income of the population, credibility of the products, research investments and regulatory practices. The characteristics of Latin America are diverse at the regional and sub-regional levels. However, as part of the demographic and epidemiological transition currently underway, common trends can be identified such as increasing urbanization and life expectancy, the occurrence of obesity and malnutrition, increasing incidences of chronic diseases and causes of mortality rates, all of which suggests the importance of diet and functional foods in public health policies. The Latin American population in general has no knowledge of functional foods, but in the more urbanized areas there is an increasingly health-conscious consumer, aware of the importance of food for health, due to the media and local traditions. More investment in research is important to explore the existing plant biodiversity that is a rich source of new foods and bioactive compounds, some of which are already used for health improvement and wellbeing. Clinical validation of functional foods should consider functional food science concepts and also the diverse cultural and genetic background of the local population. In Latin American scientific and regulatory communities, the functional foods concept has been associated with foods having health benefits beyond those of basic nutrition but is not defined officially in the emerging regulatory codes. Regulation existing in some countries is focused on safety and efficacy; both functional and health claims are allowed (risk reduction) provided they have scientific validation. This allowed introduction on the market of several products with health claims, some of them submitted to post-marketing surveillance.
\end{abstract}

Functional food: Latin America: Needs and challenges

\section{Demographic and urbanization trends in Latin America}

During the last 30 years, the declining mortality and fertility rates in Latin America have had an impact on the population's growth and structure. In 1950 the population in the Americas was 331 million and in the year 2000 it was estimated at 823 million. About one-third resides in the USA, one-third is found in Brazil (170 million) and Mexico (99 million), and the remaining third in the other countries of the region.

This demographic transition began with a decline in infant and child mortality, with most countries having halved their mortality rates among children under 1 year old in the last twenty years. Life expectancy during the last five years has stood at 70 years, with a range throughout the region from 54.1 to 79.2 years, and this change has resulted in ageing of the population, which increases chronic and degenerative diseases and disabilities. At the same time there has been an increase in the urban population, estimated now at $76 \%$, although it varies from $85.3 \%$ for the southern cone to $48.3 \%$ for Central America (Pan American Health Organization (PAHO), 1999a). In past decades mortality rates in Latin America have declined, with an increase of 18 years in life span. Although major advances have been made in controlling infectious diseases rates are still high, similar to those of non-communicable diseases, due to differences in public health care in different social groups.

\section{Nutrition in transition: globalization and its impact on nutrition patterns and diet-related diseases}

As has happened all over the world, industrialization, urbanization and market globalization have had a strong impact on Latin Americans' life-styles and diets, and the nutritional status of the population. The contemporary urbanization has resulted in a decline of undernutrition in 
metropolitan areas, but at the same time has caused increased adoption of inadequate dietary patterns and decreased physical activity. Diseases of both deficiency and excess are simultaneously important in the public health scenario. This has been called the nutrition transition.

Increased consumption of diets high in fat (particularly saturated fat), low in complex carbohydrates and less dense in micronutrients, combined with a more sedentary life-style, is responsible for spread of diet-related disorders including obesity, diabetes, cardiovascular diseases, hypertension, osteoporosis and cancer. This situation increases disabilities and premature death, placing an additional burden on public health budgets. Over the next ten years it is estimated that 11 million people in Latin America and the Caribbean will die from cardiovascular diseases, 5.7 million from cancer and 3.4 million from external causes. Nearly $23 \%$ of cardiovascular deaths and $39 \%$ of cancer deaths will occur among people under 60 years of age, representing premature mortality that can be prevented or postponed (PAHO, 1999b).

Data show that many known risk factors for noncommunicable diseases are becoming highly prevalent in Latin American and Caribbean countries. Infant malnutrition may coexist with a high prevalence rate of overweight in some adult populations, as high as $30-55 \%$ in some groups. Obesity among women is $3 \%$ in Haiti, 8-10\% in eight countries and $29 \%$ in MexicanAmericans. The prevalence of overweight among 1-5year-old children ranges from $6 \%$ in Haiti to $24 \%$ in Peru, among thirteen countries. Prevalences of overweight in children and obesity in women are greater in urban areas and in households of higher economic status (Martorell et al. 1998). Studies in Brazil have shown overweight rates as high as $30 \%$ in school children and in urban areas. The prevalence of hypertension has been estimated to range between 8 and $30 \%$ and even higher (40\%) in existing studies. High prevalence of hypercholesterolaemia $(30-40 \%)$ has been documented in some regions. The few existing studies on physical activity reported rates of sedentary life as high as 50-90\%. Even diabetes, previously uncommon in many developing countries, seems to be growing in importance with prevalence estimates of between 5 and $10 \%$. Much higher figures, up to $18 \%$, have been found in some countries of the Caribbean. In the year 2000 the number of people who suffered from diabetes in the Americas was estimated as 35 million, of which 19 million (54\%) live in Latin America and the Caribbean.

\section{Micronutrient deficiencies}

The nutrition transition changes in dietary habits are also causing nutritional deficit, resulting in marginal micronutrient deficiencies, well-known classical clinical deficiencies or both. But diseases of both deficiency and excess are simultaneously important.

Estimates of 1995 indicated over 168 million people at risk of iodine deficiency disorders (63 million affected by goitre), 15 million children under 5 years old suffering from various levels of vitamin A deficiency (20\% prevalence) and 94 million suffering from deficiency anaemia (40\% prevalence in women; PAHO, 2000). Classical deficiency affects millions of people and several countries have fortification programmes, some of which are even mandatory, like the addition of $\mathrm{Fe}$ to flour in Brazil. In urban areas, research has indicated that priorities are deficiencies of $\mathrm{Fe}, \mathrm{Zn}$ and vitamin $\mathrm{A}$ in infants and pre-school children and of $\mathrm{Fe}$, folate, $\mathrm{Ca}$ and vitamin $\mathrm{A}$ in adolescent, pregnant and lactating women (Trugo et al. 1997).

Costa Rica has better nutritional status than most other Latin American countries, with low levels of anaemia; yet half of Costa Rican adolescent girls showed anaemia and low folate intake. This shows the importance of studying specific population groups not only concerning anaemia, but also for neural tube defects and cardiovascular diseases (Monge et al. 2001). In Brazil, too, evidence based on consumption and clinical and biochemical surveys has shown the prevalence of Fe deficiency, followed by low consumption (or low availability) of folate, $\mathrm{Zn}$ and $\mathrm{Ca}$, a trend of reduced fibre intake and excessive $\mathrm{Na}$ consumption (Cozzolino, 1997). Regarding vulnerable groups and critical nutrients, the requirement may be above the potential available in foods.

As for the relationship between micronutrient status and chronic degenerative diseases, one should focus on folates, antioxidant nutrients and cardiovascular diseases, and on $\mathrm{Ca}$ and osteoporosis.

\section{Opportunities and challenges}

\section{Foods for deficiency and for excess}

Nutrition is recognized as one of the major health determinants. We have already seen that the epidemiological and nutritional situation in Latin America represents a considerable challenge for everyone involved in the different aspects of food and nutrition: university, industry and government staff, responsible for research, production and regulation, respectively.

There are needs and opportunities to produce foods for the classical clinical deficiencies, and also for the already known marginal or emerging micronutrient deficiencies of particular population sub-groups. Enriched, restored and fortified foods, as well as foods with a high bioavailability of nutrients, must be available either for government nutrition programmes or on the market. Considering that in Latin American countries the diet is frequently based on a staple like cassava, corn, potato or beans with low micronutrient density, there is borderline ingestion of several nutrients, such as folic acid, Zn, Se and Ca. Thus optimum consumption of these micronutrients in some groups may only be achieved by some kind of diet supplementation.

In this respect genetic engineering is an important tool to increase nutrient contents and bioavailability, and in some cases may be the best approach. Some examples are the introduction of vitamin $\mathrm{A}$ and also the increase in Fe content of rice. The production of foods that may improve immunological protection of infants, to prevent intestinal infections, is another way to introduce functionality in 
foods and address public health concerns in less developed countries. A group from the Biomedical Science Institute of the author's university has engineered a Lactobacillus to express Escherichia coli intimine that stimulates serum immunoglobulin A production and thus may protect infants from diarrhoea.

At the same time there is a need for foods to address specific health conditions that have become critical in Latin American countries nowadays, like the ones associated with cardiovascular problems, diseases like cancer, diabetics, obesity, osteoporosis and others. Latin America also needs foods that may help specific sub-groups of the population gain control of the risk of disease and of their well-being.

The concepts of food functionality and functional food science, as defined in Europe, seem to be the right approach to generate the knowledge necessary to help industry offer new foods in order to answer these challenges and help governments to define nutrition and adequate regulatory policies.

\section{Bioactive phytochemicals in foods and plants}

Another aspect to be considered is associated with phytochemical compounds of foods and other plants. A growing number of studies have linked diets rich in fruit and vegetables with good health, and correlations have also been found between the ingestion of some compounds, like flavonoids, carotenoids and glucosinolates, and lower risks of cancer, cardiovascular and some other chronic diseases. In Latin America there are very few data concerning the nutrient composition of foods and virtually none on non-nutrient components. Considering the low fruit consumption and the identified marginal deficiencies of micronutrients, the consumption of protective compounds may be low, calling for more research.

One can say that the discoveries of the fifteenth century introduced Latin America into the global economy and that globalization has proceeded from then on. Since then food products such as corn, beans, amaranth, quinoa, potatoes, tomatoes, cocoa, guava, papaya, avocado and many others have become an important part of the diet in many regions of the world, including Europe. The great potential of unknown or under-exploited Latin American plants is still waiting adequate research. It is estimated that in the Amazon region there are 50000 plants representing $25 \%$ of total biodiversity, but less than $2 \%$ have been studied. Many of them may be important sources of phytochemicals, flavours and colours.

Latin American plants are usually rich in flavonoids, anthocyanins and carotenoids, and some have interesting amounts and combinations of specific carotenoids like zeaxanthin, lutein and others. Some fruits like guava and palm fruits like açaí (Euterpe oleracea) have three times more lycopene than tomatoes and are also rich sources of anthocyanins (Rodriguez-Amaya, 1999). Camu-camu (Myrciaria dubia) fruit may contain 2\% ascorbic acid. Brazil nuts are the richest source of Se. Roots from some regions produce functional oligosaccharides, polysaccharides and important oils, sterols, and saponins. Maca (Lepidium meyenii), guaraná (Paulinia cupana) and mate tea (Ieia paraguayensis) are known for their energygiving properties. Many of them have important physiological and pharmacological actions. Several of these fruits are no longer just harvested but are cultivated industrially, and soon they will be economically significant.

\section{Claims, efficacy validation and human variability}

A great variety of products are available in open markets in Latin America, even in highly urbanized areas like São Paulo. They are whole plants, plant organs like leaves, tubers, seeds, fruits presented in several forms from powder to extracts, and juices, alone or in combination. They are very popular because they are part of the cultural tradition, they are perceived as 'natural' and therefore healthy, and because they are cheap. These products are sold with claims for important diseases, to help nutrition or simply for bad humour. Not much is known about the composition, safety and activity of most of them. Only recently have research projects been undertaken in a more systematic manner and these products submitted to review by health authorities.

Latin America has a very diverse cultural and genetic background. The indigenous population, for instance, can represent $40 \%$ or more in some regions and less than $1 \%$ in others. Populations with African ancestors in the Americas may vary from less than $3 \%$ in Mexico to $44 \%$ in Brazil and $84 \%$ in the Dominican Republic. The first genetic profile of the Brazilian population showed that the black people are whiter and the white people are blacker than first thought (white are partly genetically black and vice versa). Interesting data are emerging in Brazil to suggest that genes vary from region to region, where the regions also have different cultural and dietary habits (Pena, 2000). Here, differences in Apo $\mathrm{E}_{4}$ genes and $L D L \mathrm{~A}^{+} \mathrm{A}^{+}$genes are linked to coronary diseases (Cavalli et al. 2000; Salazar et al. 2000) and Apo $\mathrm{E}_{4}$ genes to high cholesterol and diabetes mostly in black people (Otta et al. 1996). This is important, for instance, in studies on cholesterol reduction by diet. All this clearly shows the importance of genetic background and human ecology considerations when evaluating the efficacy of functional foods. Even if urbanization has homogenized some habits, there is still, by and large, a significant variation in dietary habits and organism physiology in our populations, pointing to the importance of and need for local research.

Functional foods should be viewed in Latin America beyond short-term commercial prospects and consider long-term research and development, regional needs, and the cultural habits and economical level of consumers.

\section{Legislation on functional foods in Latin America: regulatory status}

Concerning functional foods, adequate legislation is essential to protect public health and stimulate technological development. In Latin America and the Caribbean, regulation concerning functional foods, functional supplements and functional and health claims differs greatly 
from country to country. There is no official or legal definition of functional foods or a specific regulation for functional foods/ingredients. In general, basic nutrient content/function claims are allowed and subject to some norms, but only a few countries allow or have norms for health claims. Even so, health authorities have allowed product claims by on a case-by-case basis in several countries.

Brazil is the only country to have a well-defined regulation for functional and health claims for either nutrient or non-nutrient components and also for the demonstration of safety and efficacy (Agência Nacional de Vigilância Sanitária, 1999). In almost all countries functional or health claims associated with non-nutrient compounds or non-essential nutrients are neither prohibited nor regulated. As a consequence, there is no legislation on efficacy and safety and also a lack of criteria for scientific substantiation of claims, except for Brazil. Even so, all over Latin America, in popular markets and even in supermarkets, hundreds of foods and drugs are sold together with curative allegation.
Considering the regional economic level, cultural identity and public health situation, the development of common functional foods concepts and norms seems to be very important. Brazilian legislation can be used as a starting point in this direction since it has been based on internationally acceptable principles and is considered to be up-to-date. In Brazil functional foods have not been defined as such but the norms were based on the idea of a food that is food and not a drug, that is part of a normal diet and that can produce benefits beyond basic nutrition. Legislation essentially rules on demonstration of the safety and efficacy of novel foods (foods not used before in Brazil) and foods/ingredients that have a claim in the label. All of these products should be registered and approved by health authorities. Safety demonstration is a priority and should be based on risk analysis, including risk assessment, management and information. Efficacy concerning the claims should be based on scientific evidence obtained from the literature or by new research and must represent scientific consensus, as has been

Table 1. Examples of food claims approved and not approved in different Latin American countries

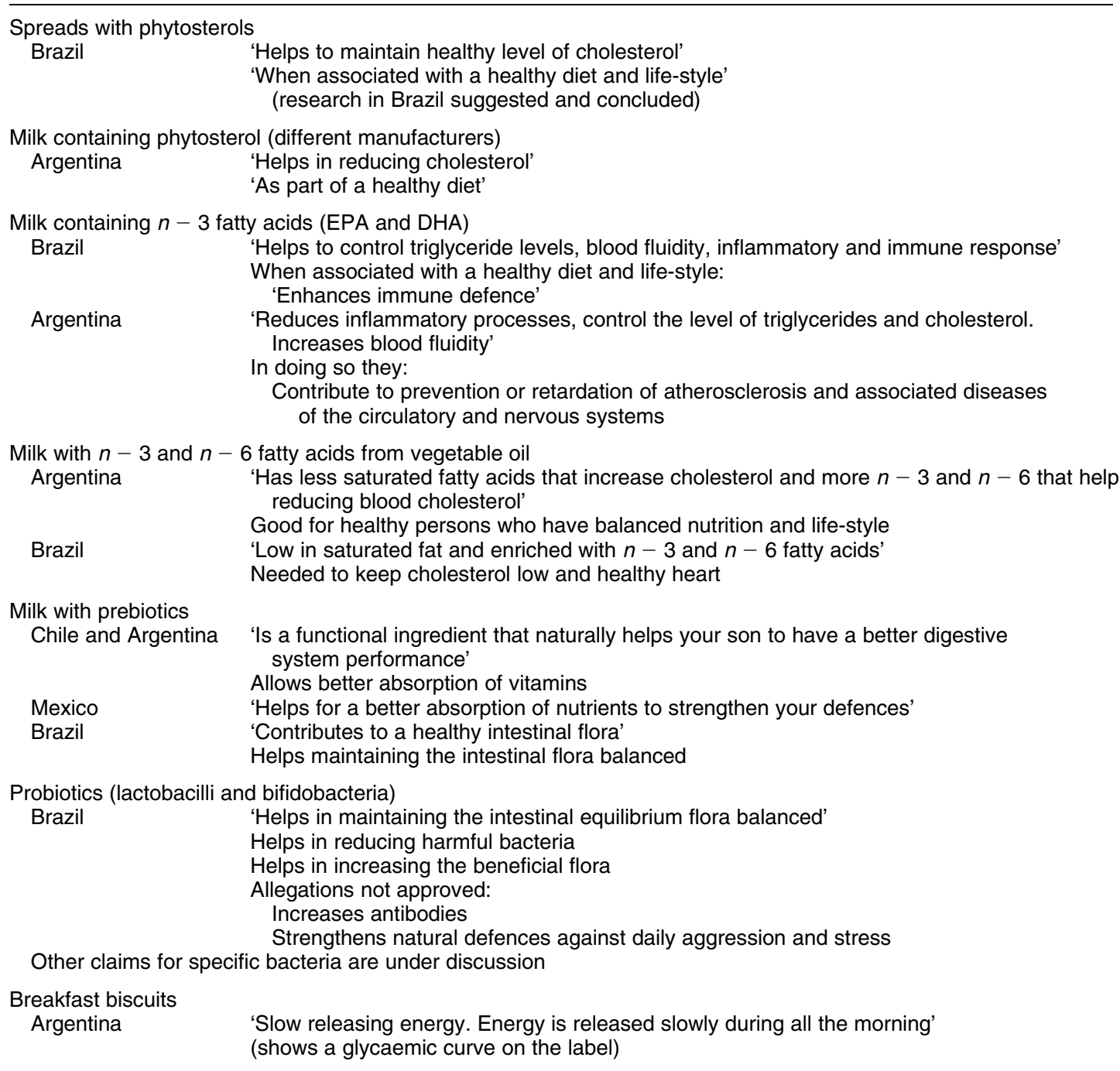


discussed by the US Food and Drug Administration and by the International Life Science Institutes in several forums and in the Codex Alimentarius.

In Brazil, both functional (enhanced function) and health claims are defined and allowed. As for health claims, only health maintenance and risk reduction claims are allowed, with both prevention and cure allegations being prohibited. In this case, however, the product can be considered as a drug and assessed as such. The label on the product should be clearly understandable by consumers, not misleading, it should inform the limitation of efficacy, and should be in accordance with public health policies. In some specific cases products should clearly inform restriction of their use to specific groups or to individuals with specific physiological conditions, as well as any adverse side-effects that may occur. These rules also apply for marketing and advertising materials.

Regarding products in pharmaceutical form that contain bioactive compounds normally present in foods, the label should inform that the product 'does not prevent or cure any disease'. Mixtures of foods and food components with herbals that have pharmacological action are considered drugs or phytotherapeutic agents, and submitted to pharmaceutical regulations.

In Brazil, like in many other countries in Latin America, there is a great use of phytotherapeutics. These include plants, plant organs, extracts, pills, etc. that by tradition or by research are known to cure or alleviate some diseases, and are classified and regulated as drugs by health authorities. Two years ago, before the existence of norms in Brazil, there were a large number of these 'natural' products being sold as foods or food supplements with unproved and undemonstrated curative claims for all known diseases. Some of them were complex mixtures of vegetable extracts containing highly active pharmacological compounds such as amphetamines. The legislation issued allowed organization of the market through the analysis for safety and efficacy of the existing 2000 products, among which only 430 are still being produced by 115 manufacturers.

\section{Foods with functional or health claims in Latin America}

During the last two years, a number of new foods that may be considered as functional foods, since they have functional or health properties acknowledged by health authorities, have appeared on the market in some countries. The most important are spreads and milks with added phytosterols, milk containing long-chain $n-3$ fatty acids and milks with added $n-3$ and $n-6$ fatty acids from vegetable oils. Milk and products with oligofructose, margarine and yoghurts containing fibre, cookies engineered to have low glycaemic index, and milks fermented with selected Lactobacillus and Bifidobacterium strains have also appeared. Other products are those containing soyabean proteins and isoflavones, low-cholesterol eggs, and energy and isotonic drinks containing caffeine and other herbal extracts.

A number of products in pharmaceutical form should also be mentioned. These are mostly fibre-containing products, antioxidants and oils containing freeze-dried vegetable/fruit extracts.

Some of the claims approved and not approved in different countries can be used as examples to illustrate the on-going legal situation in Latin America, and are shown in Table 1. As shown by these examples, almost all of the claims can be classified more as functional claims than as claims related to a disease, reflecting the present position of the health authorities. They are mostly based on internationally accepted scientific knowledge but some of them may be too sophisticated even for a well-informed public.

Latin American consumers, in general, do not know what functional foods are, although in the more urbanized areas there is an increasing number of health-conscious consumers aware of the importance of diet for health and well-being. This awareness comes either from the media or cultural tradition. Concepts associated with vitamins, obesity, cholesterol, fibre, fermented milk and physical activity are disseminated, even if the general nutrition knowledge is poor. However, long and complex claims are difficult to understand and may confuse consumers. It is necessary to disseminate the best available information and advice about diet, as part of a sound alimentary education.

In several cases, marketing information carried by the media to promote a product goes far beyond what was approved, misleading the consumer. To solve this problem some countries like Brazil are also regulating propaganda on foods. This may help give credibility to the assessment process and to the functional foods area.

While middle- and upper-class people can get their health foods at the supermarket, lower-class people can get theirs in other places where they find their functional 'garrafadas', known as natural and therefore healthy products for nutrition and healing. They both seem clearly to understand how to make use of the concept of improving their health and well-being through food.

\section{Conclusions}

The occurrence of diet-related diseases of deficiency and excess points to the importance of the development of functional food (science). In urban areas, due to the media and cultural tradition, there is increasing consumer awareness of the importance of foods for health. The perspectives of Latin America as a potential producer and consumer of functional foods will depend on the level of information and income of the population, on the creditability and pricing of products, on the nutrition and regulatory policies and on research investments. Functional food science must be viewed in Latin America beyond the short-term commercial prospects and should consider long-term research and development.

\section{References}

Agência Nacional de Vigilância Sanitária (1999) Decreto 16, 17, 18 e 19 de abril de 1999. http://www.anvisa.gov.br. Cavalli SA, Hirata MH, Salazar LA, Diament J, Forti N, Giannini 
SD, Nakandakare ER, Bertolami MC \& Hirata RDC (2000) Apolipoprotein B gene polymorphism: prevalence and impact on serum lipid concentrations in hypercholesterolemic individuals from Brazil. Clinica Chimica Acta 302, 189-203.

Cozzolino S (1997) Biodisponibilidade de minerais. Revista Puccamp 10, 877-898.

Martorell R, Kan LF, Hujlos ML \& Grummer-Strawn LM (1998) Obesity in Latin American women and children. Journal of Nutrition 128, 1464-1473.

Monge R, Raiges F \& Rivero A (2001) Iron and folates status in urban and rural Costa Rican teenagers. Food and Nutrition Bulletin 22, 45-52.

Otta MI, Cavalli SA, Hirata RDC, Lottenberg S, Quintao E \& Hirata MH (1996) Apolipoprotein E genotype frequencies in hypercholesterolemic and diabetic individuals. Clinical Chemistry 42, 839.

Pan American Health Organization (1999a) Assessment of the 1980-1998 health situation and trends in the Americas, by subregion. Epidemiological Bulletin 20, 2-10.

Pan American Health Organization (1999b) Networking for the
Surveillance of Risk Factors for Non-communicable Diseases in Latin America and the Caribbean. Paho/HCP/99.08. Washington, DC: Pan American Health Organization.

Pan American Health Organization (2000) Health situation analysis in the Americas, 1999-2000. Epidemiological Bulletin 21, 1-3.

Pena SD (2000) Research report on genetic diversity. Minas Gerais, Brazil. University Federal Minas Gerais.

Rodriguez-Amaya DB (1999) Latin American food sources of carotenoids. Archivos Latinoamericanos de Nutricion 49, $745-845$.

Salazar IA, Cavalli SA, Hirata MH, Diament J, Forti N, Giannini SD, Nakandakare ER, Bertolami MC \& Hirata RDC (2000) Polymorphisms of the low-density lipoprotein receptor gene in Brazilian individuals with heterozygous familial hypercholesterolemia. Brazilian Journal of Medical and Biological Research 33, 1301-1304.

Trugo NMF, Donangels M \& Trugo LC (1997) Micronutrient status and urban lifestyle in Brazil. Archivos Latinoamericanos de Nutricion 47, Suppl. 1, 1-50. 